\title{
AVALIAÇÃO DE AÇÕES DE GESTÃO DO CONHECIMENTO PARA SUSTENTAR A IMPLEMENTAÇÃO DA INOVAÇÃO DE VALOR
}

\section{KNOWLEDGE MANAGEMENT ACTIONS EVALUATION TO SUSTAIN THE IMPLEMENTATION OF VALUE INNOVATION}

\author{
Ricardo Monteiro de Carvalho ${ }^{1}$; Dálcio Roberto dos Reis ${ }^{2}$; Bruno Pedroso ${ }^{3}$ \\ ${ }^{1}$ Universidade Tecnológica Federal do Paraná - UTFPR - Ponta Grossa - Brasil \\ rmdecarvalho@yahoo.com.br \\ ${ }^{2}$ Universidade Tecnológica Federal do Paraná - UTFPR - Ponta Grossa - Brasil \\ dalcio@utfpr.edu.br \\ ${ }^{3}$ Universidade Tecnológica Federal do Paraná - UTFPR - Ponta Grossa - Brasil \\ brunops3@brturbo.com.br
}

\begin{abstract}
Resumo
$O$ presente trabalho evidenciou a utilização das treze ações de Gestão do Conhecimento relacionadas à dimensão "Estrutura Organizacional” de Terra $(2005,2007)$ para tornar possivel a implementação da lógica de Inovação de Valor de Kim e Mauborgne (1997, 2005), Dillon, Lee e Matheson (2005) e Aiman-Smith et al. (2005) em uma organização brasileira que tem dois modelos de negócio distintos, gráfica digital de impressão sob demanda e fornecimento de peças industriais. A bibliografia consultada girou em torno dos autores Kim e Mauborgne e de diversos autores de Gestão do Conhecimento. Esta investigação é aplicada, quantitativa, exploratória e indutiva. $O$ instrumento utilizado para a coleta de dados foi um questionário baseado nas cem ações de Gestão do Conhecimento de Terra (2007). Os resultados demonstram que a Organização Alpha possui oito ações de Gestão do Conhecimento utilizadas em nível elevado que torna possível a implementação da Inovação de Valor. No entanto é necessário a implementação de políticas organizacionais visando a elevação do nível de utilização das ações de Gestão do Conhecimento vinculadas à dimensão "Estrutura Organizacional". Há uma oportunidade de melhoria para redução das diferenças de percepções da alta administração e dos demais colaboradores, pois duas ações tiveram percepções bastante distintas, uma vez que, por meio da redução das diferenças de percepções, possibilita-se criar um ambiente propício para a implementação da Inovação de Valor. A organização objeto de estudo deve implementar politicas baseadas nos conceitos e princípios de Inovação de Valor, para que as ações de Gestão de Conhecimento possam ser melhor utilizadas e, desta forma, gerar riqueza e alto crescimento.
\end{abstract}

Palavras-chave: ações de gestão do conhecimento, estrutura organizacional, inovação de valor. 


\section{Introdução}

Organizações dos mais distintos ramos de atuação, têm recentemente tentado adotar as melhores ações de Gestão do Conhecimento objetivando tornar-se mais competitivas em um cenário organizacional muito complexo, globalizado e recessivo. Para tentar implementar a Inovação de Valor, algumas organizações líderes começaram a prestar mais atenção na Gestão do Conhecimento, visando criar, reter, compartilhar e transferir conhecimento para o ambiente organizacional.

Mesmo organizações líderes, têm se deparado com o fato de que seus produtos e serviços, embora apresentem tecnologia e qualidade, tornaram-se commodities. Neste complexo e competitivo cenário a variável preço tornou-se determinante na relação business to business ocorrida entre clientes e fornecedores. A inovação em suas mais diversas facetas e conceitos tem desempenhado papel importante na evolução deste cenário e tem determinado as diretrizes e tendências.

Para fazer a diferença e criar uma nova forma de gerar riqueza e alto crescimento, a Inovação de Valor começou a desempenhar um importante papel nas diretrizes estratégicas organizacionais. Conforme Dillon, Lee e Matheson (2005), diversas organizações supervalorizam a Inovação Tecnológica, crendo que esta, por si só, é suficiente para gerar nova riqueza. Analisando os investimentos realizados anualmente em Pesquisa e Desenvolvimento (P\&D) pelas principais organizações investidoras em $\mathrm{P} \& \mathrm{D}$, a contribuição do $\mathrm{P} \& \mathrm{D}$ é apenas uma porção dos investimentos e em alguns casos pode ser igual a zero. Este dado mostra que a Inovação Tecnológica por si só não garante a geração de riqueza. Baseado nisto, a Inovação de Valor desempenha importante papel no ambiente organizacional.

Há uma concordância de que a Inovação é a força motriz de uma organização. O subcomitê Research on Research, ligado ao Instituto de Pesquisa Industrial dos Estados Unidos, se deu conta, em 1999, que o foco somente em desenvolvimento e comercialização de novas tecnologias não seria suficiente para uma organização tornar-se inovadora. De acordo com este estudo, foi necessário ocorrer Inovação por toda a cadeia de valor, incluindo marketing, pesquisa de mercado, vendas, publicidade, distribuição e serviço para a geração de nova riqueza (AIMAN-SMITH et al., 2005).

O presente trabalho de pesquisa tem como objetivo responder a seguinte pergunta: "Qual é o nível de utilização das treze ações de Gestão do Conhecimento, relacionadas à dimensão "Estrutura Organizacional”, que poderiam influenciar na capacidade de criar um ambiente propício à implementação da Inovação de Valor?” A organização objeto deste estudo, designada Organização Alpha, adota diversas ações de Gestão do Conhecimento em elevado nível, tornando possível a 
criação de um ambiente propício à implementação da Inovação de Valor no cenário competitivo vigente.

Um dos principais benefícios usufruídos pela Organização Alpha é a aplicabilidade das ações de Gestão do Conhecimento relacionadas à dimensão "Estrutura Organizacional” e aplicação de um plano de ação para corrigir os eventuais desvios oriundos entre a percepção da alta administração e a percepção dos demais colaboradores.

Verificou se que a Organização Alpha possui condições para criar um ambiente propício para a implementação da Inovação de Valor. Em 2005, Kim e Mauborgne publicaram o livro A Estratégia do Oceano Azul baseado na teoria de Inovação de Valor. Organizações de renome mundial passaram a incorporar os preceitos da teoria de Inovação de Valor. Uma delas, a KimberlyClark, por meio do Kimberly-Clark Blue Ocean Strategy Institute do Brasil, está conseguindo disseminar a filosofia da Inovação de Valor por toda a organização, fazendo com que esta filosofia torne-se parte do DNA cultural desta organização.

O presente trabalho objetiva, através das evidências da utilização das treze ações de Gestão do Conhecimento relacionadas à dimensão "Estrutura Organizacional” de Terra (2005, 2007), verificar qual é o nível de adoção destas ações que poderiam influenciar positivamente na implementação da Inovação de Valor na Organização Alpha.

Este trabalho de pesquisa focou unicamente na dimensão "Estrutura Organizacional" para verificar o impacto das ações relacionadas à esta dimensão na cultura organizacional vigente para propor alternativas para criar um ambiente propício à implementação da Inovação de Valor. Para Kim e Mauborgne (1997), o principal objetivo da Inovação de Valor é minimizar os impactos da concorrência e desenvolver alto crescimento sustentável, criando desta forma um modelo de negócios difícil de ser seguido.

\section{Referencial teórico}

Nesta seção são abordados os conceitos de Gestão do Conhecimento, Estrutura Organizacional, Inovação de Valor, Liderança no Ponto de Desequilíbrio e Barreiras Organizacionais. De acordo com Kim e Mauborgne (1997, 2005) a Inovação de Valor é a principal razão para o sucesso de organizações que querem conquistar incontestável espaço de mercado e enfraquecer a concorrência. Para que isto se torne possível, faz-se necessário a compreensão dos conceitos e definições a seguir.

\section{Impactos positivos da gestão do conhecimento na geração de riqueza}


No século XXI, a sociedade pós-capitalista chamada por Drucker de Sociedade do Conhecimento, passou a requerer um tipo de indivíduo qualificado que tenha a habilidade de entender os diferentes tipos de conhecimento. Drucker (2007) propôs diversas questões a cerca deste tema, dentre as quais consideram-se: Do que trata cada conhecimento? O que se está tentando fazer? Quais são as preocupações centrais e teorias? Quais principais insights têm sido produzidos? Quais são as áreas importantes de ignorância, seus problemas, seus desafios? Drucker também enfatiza que todos os conhecimentos são igualmente valiosos e significativos para a definição dos padrões de conhecimento e devem ser de responsabilidade daqueles que detém o conhecimento. Vale ressaltar que boa parte dos indivíduos trabalha em organizações vinculadas à sociedade do conhecimento. Também não pode ser esquecido que, na sociedade do conhecimento, os empregados, denominados também de colaboradores, são trabalhadores do conhecimento. Invariavelmente, quanto mais rentável for o investimento na sociedade do conhecimento, menor será o investimento em equipamentos ou ferramentas na mesma proporção, salientando que o melhor investimento a ser feito por uma organização, é o investimento no trabalhador do conhecimento.

A Sociedade do Conhecimento tem realizado rapidamente mudanças na vida dos trabalhadores do conhecimento. As organizações passaram a prestar mais atenção nos colaboradores e eles na sua própria educação e qualificação, ao invés gastar seu tempo com trabalhos mecânicos e rotineiros.

Uma sociedade que possui organizações que investem no crescimento constante de seus estoques de conhecimentos, constatam que as habilidades dos indivíduos pertencentes a estas organizações e as instituições que promovem a troca de conhecimentos, se dão conta que tal troca propiciará um brilhante e próspero futuro para os indivíduos pertencentes a esta sociedade (CHESBROUGH, 2006).

Desde a década de oitenta, as teorias gerenciais têm apontado para a importância da sociedade do conhecimento. As organizações que desejam competir dinamicamente neste ambiente altamente mutável devem estar aptas a gerar informações e conhecimento, não somente processálos eficientemente. O indivíduo que detém o conhecimento na organização não deve ser um agente passivo, mas tornar-se ele mesmo agente de inovação. Para entender a inovação, é necessário entender a teoria do conhecimento organizacional (NONAKA; TAKEUCHI, 1995).

De acordo com Nonaka e Takeuchi (1995), a chave da criação do conhecimento organizacional está relacionada com a capacidade de mobilização e conversão do conhecimento tácito. Estes apresentam quatro formas de conversão do conhecimento, demonstrando as interações entre o conhecimento tácito e explícito. Estas quatro formas, chamadas de SECI (Sociabilização, Externalização, Combinação e Internalização), constituem-se no motor da criação do conhecimento. 
O resultado desta espiral do conhecimento é classificada por Nonaka e Takeuchi por dimensão epistemológica.

Sobre a dimensão ontológica há três condições para promover a criação do conhecimento (Intenção organizacional, Autonomia, Flutuação e caos internos e externos, Redundância de informações, Diálogo e reflexão coletiva e Variedade de requisitos). Também há cinco fases para desenvolver o processo de criação do conhecimento (Compartilhamento de conhecimento tácito, Criação de conceitos, Justificação de conceitos, Construção de um arquétipo e Difusão interativa do conhecimento). A criação de conhecimento é um processo que nunca termina, este processo requer inovação contínua. A criação do conhecimento é o combustível para obter a inovação, mas o conhecimento por si só não é suficiente. O novo conhecimento criado na organização é a pedra fundamental de atividades inovativas (NONAKA; TAKEUCHI, 1995).

Nesta pesquisa, foi utilizado o termo Gestão do Conhecimento inúmeras vezes, entretanto neste trabalho os autores estão inclinados a concordar com o ponto de vista de Nonaka e Takeuchi sobre o conceito de Criação do Conhecimento.

O Conhecimento trata-se de uma mistura fluída de experiências condensadas, valores, informação contextual e insights experimentados, que propõem uma estrutura para a avaliação e incorporação de novas experiências e informações. O Conhecimento tem origem e é aplicado na mente dos pensadores de uma organização. Este conhecimento costuma ser incluído além de documentos e repositórios, também em rotinas, processos, práticas e regras organizacionais (DAVENPORT; PRUSAK 2003).

Davenport e Prusak na definição acima enfatizam que, primeiramente, todo conhecimento é tácito e na seqüência torna-se explícito. Os personagens centrais desta definição são as pessoas. Estes autores vêem o conhecimento sobre um ponto de vista humanístico.

Gestão do Conhecimento significa que é necessário organizar as principais políticas, processos, gestão e ferramentas tecnológicas visando uma melhor compreensão da geração, identificação, validação e processo de compartilhamento. Além de utilizar o conhecimento estratégico para gerar resultados numéricos para a organização e benefícios para os colaboradores (TERRA, 2007).

Terra enfatiza o conhecimento sob uma abordagem organizacional e enxerga o conhecimento como algo que pode ser controlado. Apesar disto, Nonaka e Takeuchi (1995) relatam que o gerenciamento do Conhecimento pode comprometer a criação do conhecimento, tornando a criação do conhecimento um processo burocrático.

O processo de Criação do Conhecimento pode ser executado pelos indivíduos conectados ao sistema de conhecimento organizacional particular. O conhecimento adquirido pelos trabalhadores do conhecimento na sua vida laboral influencia e pode trazer benefícios para seus colegas de 
trabalho e uma larga escala de conhecimentos para toda a organização (NONAKA; VON KROGH; VOELPEL, 2006).

Nas últimas duas décadas tem sido aumentado o interesse acadêmico e gerencial para a criação do conhecimento organizacional. A comunidade acadêmica tem desempenhado um importante papel no desenvolvimento e no teste de teorias da criação do conhecimento ao longo dos anos. Há a necessidade de examinar os mecanismos e processos através do conhecimento. Conhecimento é o recurso mais valioso de uma organização, entretanto poucas organizações entendem a importância deste valioso recurso (REIS, 2008).

Na rotina diária da organização, o conhecimento tem uma importância relevante. Através do conhecimento uma organização pode desenvolver produtos, serviços, modelos de negócios inovativos e uma grande escala de melhorias. O conhecimento tornou-se o centro de discussão entre acadêmicos, consultores, gerentes e escritórios governamentais. A maioria das organizações se deu conta que elas necessitam investir tempo, pessoas e recursos para melhorar e criar conhecimento. A criação do conhecimento é o motor da inovação em suas diferentes faces, definições e aspectos.

A inovação é baseada no processo de conhecimento, criando novas possibilidades, combinando conhecimento e se dando conta que é possível atender e articular uma necessidade evidenciada (TIDD; BESSANT, PAVITT, 2005).

Tidd, Bessant e Pavitt enfatizam a premissa de que conhecimento é o combustível da inovação, como mencionado por Nonaka e Takeuchi e, por causa disto, os gestores estão muitos mais preocupados e estão dispensando muito mais tempo para entender esta questão. Na realidade, há uma estreita relação entre conhecimento e inovação, pode-se considerar que o conhecimento é o primeiro passo para atingir a inovação. Há uma probabilidade remota de se alcançar a Inovação sem a Gestão do Conhecimento.

No dia-a-dia organizacional, o conhecimento é o fator chave para atingir a Inovação. Sem conhecimento, a dificuldade para uma organização obter sucesso torna-se maior, ambos são relacionados e essenciais para a implementação da Inovação de Valor que é a pedra angular para tornar a competição irrelevante de acordo com a teoria criada por Kim e Mauborgne $(1997,2005)$.

O termo tornar a competição irrelevante é um termo bastante controverso e forte. Nesta pesquisa ele será interpretado como tornar o ambiente mais difícil de ser copiado e seguido pela concorrência.

A Inovação de Valor tem o objetivo de construir barreiras para evitar competidores e construir valor relevante para o cliente mais importante na cadeia de valor de acordo com AimanSmith et al. (2005).

O processo de acesso ao conhecimento origina-se do conhecimento adquirido de outras culturas e neste contexto as nações são importantes para a criação e a evolução de um 
empreendimento (KUEMMERLE, 2002).

O processo de acesso ao conhecimento está também relacionado onde o empreendimento se encontra. Qualquer país, estado ou cidade tem idiossincrasias relacionadas à sua própria cultura. A organização objeto deste estudo de pesquisa está localizada nas cidades paranaenses de Palmeira, Ponta Grossa e Curitiba e certamente há aspectos culturais que influenciam no processo de criação do conhecimento, no dia-a-dia do trabalho e no comportamento organizacional, podendo tornar mais fácil ou difícil implementar a Inovação de Valor.

$\mathrm{Na}$ Estrutura Organizacional, o conhecimento é um dos aspectos chave no Planejamento Estratégico. Para garantir o sucesso da organização, gerentes e diretores estão despendendo mais recursos para desenvolver e reter talentos dentro da organização. Finalmente estes executivos se deram conta de quão importante são os indivíduos e como eles podem fazer a diferença no sucesso ou no fracasso da estratégia organizacional. Há uma forte conexão entre o conhecimento criado pelos colaboradores de uma organização e as inovações desenvolvidas por esta organização.

A próxima seção está relacionada com uma das sete dimensões do conhecimento de Terra (2005, 2007), a dimensão "Estrutura Organizacional”. Esta dimensão foi medida através das treze ações de Gestão do Conhecimento que objetivaram avaliar se é possível ou não criar um ambiente propício à implementação da Inovação de Valor.

\section{Estrutura Organizacional}

Organizações devem adaptar suas estruturas organizacionais primeiramente para permitir a criação e a transferência do conhecimento da melhor forma possível. Os modelos organizacionais são imperativos em uma organização. A evolução envolvendo o ambiente e as diferentes estruturas organizacionais afetam diretamente as organizações (CORTES; SAEZ; ORTEGA, 2007).

A Estrutura Organizacional tem desempenhado importante papel no processo de criação do conhecimento, porque ela exerce grande influência na capacidade de propiciar o ambiente necessário à criação e transferência do conhecimento. Organizações que têm a capacidade de criar ambientes propícios possuem maior possibilidade de desenvolver condições para atingir e implementar a Inovação de Valor.

Não pode ser afirmado que há uma estrutura organizacional ideal para facilitar a criação e o compartilhamento do conhecimento, de acordo com os estudos realizados por Cortes (2007), com seis organizações espanholas. Algumas destas organizações possuem hierarquização horizontal e outras possuem hierarquização vertical. Baseado nestes estudos pode-se considerar que a estrutura tem influência na disseminação do conhecimento, mas não pode ser afirmado qual é a estrutura organizacional ideal para as organizações em geral que desejam inovar. 
Há alguns aspectos culturais que influenciam neste processo. De acordo com Aiman-Smith et al. (2005) e Dillon, Lee e Matheson (2005) os aspectos culturais têm expressiva influência na capacidade de uma organização gerar Inovação de Valor.

Para Terra $(2005,2007)$ as Sete Dimensões do Conhecimento são Fatores Estratégicos e Papel da Alta Administração; Cultura e Valores Organizacionais; Estrutura Organizacional, Administração de Recursos Humanos; Sistemas de Informação; Mensuração de Resultados e por fim Aprendizado com o Ambiente.

Neste trabalho de pesquisa está descrito a dimensão do conhecimento, Estrutura Organizacional, representada em treze ações de Gestão do Conhecimento conforme Terra (2005, 2007). Estas treze questões estão fortemente relacionadas com os conceitos de estrutura organizacional e são apresentadas a seguir:

1. Há um uso constante de equipes multidisciplinares e formais que se sobrepõem à estrutura formal tradicional e hierárquica.

2. Há um uso constante de equipes temporárias, com grande autonomia, totalmente dedicadas a projetos inovadores.

3. Pequenas reorganizações ocorrem com freqüência, de forma natural, para se adaptar às demandas do ambiente competitivo.

4. Realizam-se, com freqüência, reuniões informais, fora do local de trabalho, para a realização de brainstorms.

5. Existem várias Comunidades de Prática e de Aprendizado bem estruturadas e com a participação de um número relevante de pessoas.

6. É crescente o número de pessoas com responsabilidades específicas em termos de classificação, organização, codificação e proteção de informações e conhecimentos estratégicos para a organização.

7. Há um esforço sistemático de benchmark interno.

8. Todos os projetos/iniciativas da organização incluem uma etapa formal dedicada a discutir lições aprendidas e para documentá-las.

9. Os lay-outs são conducentes à troca informal de informação (uso de espaços abertos e salas de reunião). São poucos os símbolos de status e hierárquicos.

10. Existem mecanismos e processos formais bem estabelecidos e divulgados para todos os níveis da organização no sentido de capturar, encaminhar e facilitar a implementação de idéias de melhorias e inovações.

11. "As decisões são tomadas no nível mais baixo possível. O processo decisório é ágil; a burocracia é mínima." 
12. Os processos e projetos da organização são bem documentados e úteis para o aprendizado organizacional (não são um mero exercício burocrático e para obtenção de certificação).

13. A organização tem métodos bem estabelecidos e disseminados para solução de problemas, geração de idéias, etc.

\section{Inovação de Valor}

O conceito de Inovação de Valor é a pedra angular da estratégia do oceano azul, teoria criada por Kim e Mauborgne (1997, 2005). Posteriormente Aiman-Smith et al. (2005) e Dillon, Lee e Matheson (2005) complementaram a teoria de Inovação de Valor com o conceito de entregar valor excepcional ao cliente mais importante da cadeia de valor. A Inovação de Valor é uma nova forma de pensamento sobre a execução estratégica. Ela resulta na criação de novos espaços de mercado e pretende tornar a concorrência irrelevante. A Inovação de Valor desafia os dogmas gerenciais usuais, que são baseados na competição da relação de troca valor-custo.

A Inovação de Valor trata de criar valor excepcional para o cliente, quando aquele cliente é o cliente mais importante da cadeia de valor. A Inovação de Valor pode acontecer com ou sem inovação tecnológica e em qualquer tipo de organização de uma forma sustentável. Ela pode acontecer em um produto, serviço ou entrega (DILLON; LEE; MATHESON, 2005).

O Subcomitê de Pesquisa Research on Research, usou o termo Inovação de Valor para identificar a Inovação que acontece quando os colaboradores da organização estão trabalhando para identificar novas e melhores formas para servir os atuais clientes e identificar a possibilidade para desenvolver novos mercados (AIMAN-SMITH et al., 2005).

Conforme Hübler e Pereira (2005), a Inovação é o fator chave para aquelas organizações que pretendem conquistar ou manter espaços de mercado ou posição contra a concorrência, entretanto há grandes desafios impostos pela a concorrência.

Boa parte dos autores que falam sobre competição, usam conceitos e taxionomias similares ao militarismo. Os estrategistas tradicionais vêem a estratégia como uma batalha, em que alguém tem que ser derrotado. Neste caso tais estrategistas querem conquistar mais e mais espaços de mercado e derrotar a concorrência, muitas vezes sacrificando suas margens. A Inovação de Valor é uma forma distinta de ver a estratégia, contestando a lógica vigente sustentada na forte competição.

A Inovação de Valor resulta em grande exercício mental aos gestores, porque no mundo dos negócios, as organizações utilizam estratégias similares e competem entre si, optando por preço ou qualidade. Outra forma de explicar o conceito de Inovação de Valor pode ser visto na figura 1, construída pelos autores Kim e Mauborgne (2005): 


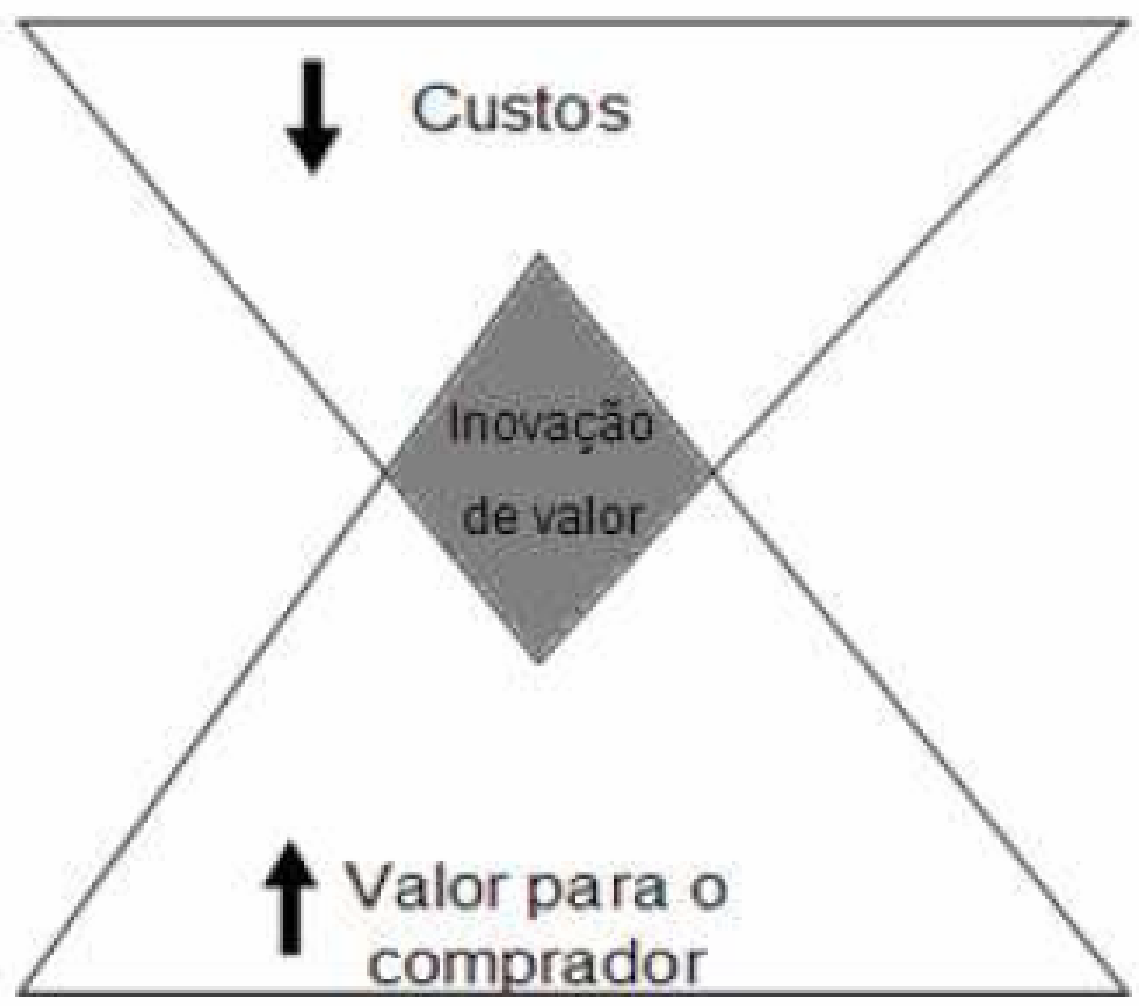

Fonte: Kim e Mauborgne (2005)

De acordo com Kim e Mauborgne (2005), organizações que objetivam alcançar crescimento de dois dígitos, devem prestar menos atenção em bater ou vencer a concorrência, elas devem tornar a concorrência irrelevante através da lógica de Inovação de Valor.

Retornando ao conceito de Kim e Mauborgne (2005) que a Inovação de Valor torna a concorrência irrelevante, mais uma vez, o termo utilizado é realmente um termo bastante forte e controverso. Nesta pesquisa houve uma concordância de percepção com os autores em um primeiro momento, pois a concorrência enfrentará dificuldades para copiar a lógica de Inovação de Valor. Os inovadores de valor terão vantagem porque eles serão os primeiros a inovar, mas cedo ou tarde a concorrência tentará copiar a mesma estratégia ou modelo de negócios utilizados. A Inovação de Valor desenvolve-se naquelas organizações que podem criar novos espaços de mercado, além de evitar e retardar os efeitos da concorrência. Para garantir o sucesso da Inovação de Valor faz-se necessário sua renovação constante, uma vez que o processo de Inovação de Valor é um processo contínuo e busca o alto crescimento sustentável. Adotando atitudes que visam a inovação contínua, tal comportamento permite a construção de barreiras para tornar mais difícil para a concorrência de seguir os passos dos inovadores de valor.

Conforme Kim e Mauborgne (1997) a Inovação de Valor consiste em perseguir valor radicalmente superior para os clientes e baixo custo para as organizações. O foco está no que 
realmente é importante para os clientes e como a organização pode ganhar dinheiro reduzindo custos.

Para a compreensão das diferenças mencionadas entre a lógica convencional e a lógica da Inovação de Valor, faz-se necessário comparar as diferenças descritas no quadro 1:

Quadro 1-Duas lógicas estratégicas

\begin{tabular}{|l|l|l|}
\hline \multicolumn{1}{|c|}{$\begin{array}{c}\text { As Cinco } \\
\text { Dimensões da } \\
\text { Estratégia }\end{array}$} & \multicolumn{1}{|c|}{ Lógica Convencional } & \multicolumn{1}{c|}{ Lógica da Inovação de Valor } \\
\hline $\begin{array}{l}\text { Controle da } \\
\text { Indústria }\end{array}$ & As condições da Indústria são dadas. & As condições da Indústria são moldadas. \\
\hline Foco Estratégico & $\begin{array}{l}\text { Uma empresa deve construir as } \\
\text { vantagens competitivas. }\end{array}$ & $\begin{array}{l}\text { Competição não é benchmark. Uma empresa } \\
\text { deve perseguir uma curva de valor para } \\
\text { dominar o Mercado. }\end{array}$ \\
\hline Clientes & $\begin{array}{l}\text { Uma empresa deve reter e expandir } \\
\text { sua base de clientes através da da } \\
\text { segmentação e customização. Deve } \\
\text { focar-se nas diferenças que os clientes } \\
\text { valorizam. }\end{array}$ & $\begin{array}{l}\text { Um inovador de valor almeja a massa de } \\
\text { compradores e deixa alguns consumidores } \\
\text { existentes partirem. O foco está nas } \\
\text { similaridades que o consumidor valoriza. }\end{array}$ \\
\hline $\begin{array}{l}\text { Vantagens e } \\
\text { Capacidades }\end{array}$ & $\begin{array}{l}\text { Uma companhia deve influenciar as } \\
\text { vantagens e capacidades existentes. }\end{array}$ & $\begin{array}{l}\text { Uma empresa não deve ficar constrangida } \\
\text { pelo "O que nós deveríamos fazer se } \\
\text { começássemos novamente?" }\end{array}$ \\
\hline $\begin{array}{l}\text { Produtos e Serviços } \\
\text { Ofertados }\end{array}$ & $\begin{array}{l}\text { As fronteiras tradicionais da indústria } \\
\text { determinam produtos e serviços que a a } \\
\text { empresa oferece. O objetivo é é } \\
\text { maximizar o valor destas ofertas. }\end{array}$ & $\begin{array}{l}\text { Um inovador de valor pensa em termos de } \\
\text { solução total para as necessidades dos } \\
\text { clientes, mesmo se leva os clientes além das } \\
\text { ofertas tradicionais da indústria. }\end{array}$ \\
\hline
\end{tabular}

Fonte: Kim e Mauborgne (1997, 2005)

Para tornar o conceito de Inovação de Valor ainda mais compreensível e entender a razão da necessidade de se criar um ambiente propício à sua implementação, faz-se necessário compreender a liderança no ponto de desequilíbrio e as barreiras organizacionais, porque ambas exercem uma grande influência no processo de implementação da Inovação de Valor.

\section{Liderança no Ponto de Desequilíbrio}

A Liderança no Ponto de Desequilíbrio (LPD) cria as condições necessárias para derrubar as quatro barreiras organizacionais que proporcionam difíceis obstáculos para a implementação da lógica da Inovação de Valor. Quando os gestores utilizam a LPD, eles implementam a Inovação de Valor rapidamente e com baixo custo, ao mesmo tempo que esta liderança conquista o apoio dos colaboradores para romper o status quo vigente (KIM; MAUBORGNE, 2005).

A liderança organizacional utiliza um processo de quatro passos que possibilita a implementação da Inovação de Valor de forma rápida, mesmo com limitados recursos. A barreira cognitiva e de recursos representa aqueles obstáculos que as organizações enfrentam na reorientação e na formulação de uma nova estratégia. A barreira motivacional e a política fornecem 
o ambiente necessário para rápida execução da estratégia. Derrubando todas as quatro barreiras conquista-se a reorientação e execução estratégica rapidamente. Vencer as quatro barreiras organizacionais de forma contínua permite uma execução da Inovação de Valor de forma mais rápida, uma vez que a inovação de hoje, cedo ou tarde se tornará a norma convencional de amanhã. A comunicação estratégica dos gestores tem um importante papel na quebra das barreiras organizacionais. Tradicionalmente comunicações internas são muitas vezes baseadas em memorandos, boletins e outros documentos burocráticos. Na utilização desta comunicação burocrática, os gestores são conscientes que os colaboradores têm a triste inclinação de jogar estes documentos fora e não levar em consideração o conteúdo dos mesmos (KIM; MAUBORGNE, 2003).

Baseado nisto, a comunicação tem um importante papel na implementação da Inovação de Valor conforme figura 2.

Figura 2: Liderança no Ponto de Desequilíbrio
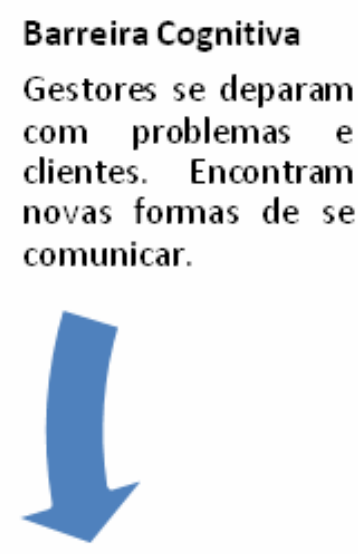

Barreira de Recursos

Focam nos pontos quentese barganham com os parceiros da organização.
Barreira Politica

Identificame silenciam oponentes internos; isolam os oponentes externos.

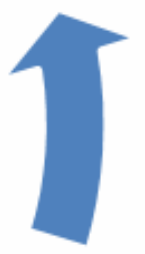

Barreira Motivacional

Colocam os holofotes sobre os líderes. Tem o desafio de atingir os vários níveis organizacionais.

Fonte: Adaptado de Kim e Mauborgne (2003)

As quatro barreiras a que os gestores freqüentemente são submetidos usualmente bloqueiam o alto desempenho. Dificuldades como a organização atrelada ao status quo vigente, limitação de recursos, equipe desmotivada e oposição clara de poderosos interesses não declarados dentro da organização, tornam difícil para os gestores atingirem a Inovação de Valor. Para implementar a Inovação de Valor, não se deve somente depender da personalidade do líder, mas também da aplicação do método que poderá ser replicado. A LPD é passível de ser aprendida (KIM; 
MAUBORGNE, 2003).

Para implementar a Inovação de Valor é necessário derrubar as barreiras cognitivas que evitam que a organização reconheça a necessidade essencial da mudança radical. Há limitações endêmicas de recursos que os gestores podem transformar em vantagens para si próprios. A barreira motivacional pode desencorajar e desmoralizar até mesmo o mais engajado colaborador. O último e mais desafiador recurso é a barreira política, mostrando como os gestores podem fornecer fatal e potente resistência de poderosos e influentes rivais (KIM; MAUBORGNE, 2003).

\section{1 Barreira cognitiva}

A LPD não confia ou toma decisões baseado somente em números para romper as barreiras cognitivas da organização. Ao invés disto, a LPD provoca situações para colocar seus principais gestores cara a cara com os problemas operacionais. Seguindo estes passos, estes gestores não podem evadir-se ou distorcer a realidade. Para corrigir um mau desempenho, todo mundo dentro da organização deve ser convencido não somente de que a reviravolta é urgentemente necessária, mas que é uma solução que todos devem alcançar (KIM; MAUBORGNE, 2003).

\section{2 Barreira de recursos}

Uma vez que os colaboradores aceitam a necessidade e clamam por mudança e que todos os envolvidos no processo de execução concordam quais necessidades devem ser atendidas, os líderes organizacionais freqüentemente enfrentam a dura realidade da limitação de recursos, inerente em tantas organizações. A pergunta feita por eles mesmos é: nós temos os valores necessários para implementar as mudanças? O senso comum entre os líderes que seguem a estratégia normal de inovação, diferente da Inovação de Valor, tomam dois tipos de decisão. A primeira decisão consiste que os gestores esquecem suas ambições, liderando a organização para a mediocridade e desmoralizando assim a força de trabalho. A segunda decisão consiste no senso comum de procurar por mais recursos de instituições financeiras, processo este que pode tomar tempo e desviar a atenção para problemas subjacentes que necessitam também serem resolvidos, deixando de lado ações que são necessárias para implementar a Inovação de Valor (KIM; MAUBORGNE, 2003).

Inovadores de valor sabem como alcançar a liderança do ponto de desequilíbrio da organização sem recursos extras. Eles podem realizar um grande negócio com os recursos que dispõem, negociando recursos dentro da própria organização. Estes líderes concentram recursos em lugares em que a maioria necessita de mudança e trás os maiores recursos possíveis (KIM; MAUBORGNE, 2003). 


\section{3 Barreira motivacional}

Alertando aos colaboradores da necessidade por mudança e identificando como isto pode ser alcançado, além da barreira adicional de limitação de recursos, é necessário alcançar a LPD da organização. Os colaboradores não devem somente reconhecer quais necessidades devem ser realizadas, eles devem também querer fazê-lo. Muitos gestores reconhecem a importância de manter os colaboradores motivados para fazer as mudanças necessárias, mas usualmente, estes gestores cometem o erro de dirimir esforços para incentivar todos os colaboradores da organização. Neste caso o processo todo pode tomar muito tempo para ser implementado e pode se tornar caro. Baseado neste limitante, os líderes devem concentrar esforços nos influenciadores chave dentro da organização e estes se encarregarão de propagar as ações necessárias (KIM; MAUBORGNE, 2003).

\section{4 Barreira política}

Política organizacional é uma difícil e inescapável realidade dentro das organizações. É muito importante entender a intriga e a política envolvida quando uma organização decide mudar seu rumo estratégico. Até mesmo se a organização alcança o ponto de desequilíbrio, poderosos interesses não declarados apresentarão barreiras tentando impedir as reformas necessárias. Tão breve as mudanças se tornem reais, mais ferozmente estes influenciadores negativos expõem seus desejos, tanto internos quanto externos, tentando proteger as suas posições, e a resistência fornecida por estes influenciadores negativos podem danificar seriamente todo o processo de mudança (KIM; MAUBORGNE, 2003).

Líderes devem compartilhar o crédito de seus sucessos com sua equipe. A teoria da liderança no ponto de desequilíbrio tenta apresentar a fórmula para levar os gestores a transformarem suas organizações, mas que também tem pouco tempo e recursos para fazer as mudanças necessárias (KIM; MAUBORGNE, 2003).

\section{Metodologia}

Esta pesquisa classifica-se como de natureza aplicada, a respeito do problema foi de natureza quantitativa, sobre os objetivos foi exploratória e o método utilizado foi o indutivo. Neste trabalho de pesquisa foi utilizado um questionário como instrumento de coleta de dados, onde foram aplicadas cem perguntas relacionadas às sete dimensões do conhecimento de Terra (2007). Neste trabalho são expostas apenas treze questões relacionadas com uma das sete dimensões do conhecimento, a Estrutura Organizacional. O questionário foi aplicado na "alta administração" e nos chamados "demais colaboradores" da Organização Alpha. O instrumento objetiva constatar as 
evidências e medir as ações de Gestão do Conhecimento de acordo com o ponto de vista da alta administração e dos demais colaboradores para tornar possível a análise se há ou não possibilidade ou potencial de gerar um ambiente propício à implementação da Inovação de Valor.

Sobre o questionário, foi utilizado o critério de pontuação baseado na escala Likert, sendo as notas de 1 a 5 , onde 1 representa discordo totalmente; 2 discordo; 3 não concordo, nem discordo; 4 concordo e 5 concordo totalmente.

O questionário foi aplicado na Organização Alpha, visando verificar se há ambiente propício para a implementação da Inovação de Valor. São apresentadas as evidências da aplicação do questionário na seção "resultados".

A organização Alpha possui um quadro de 31 colaboradores, distribuídos em três unidades. Nesta pesquisa foram avaliadas as perspectivas de 19 colaboradores, sendo quatro deles vinculados à alta administração (diretores e gerentes) e os demais 15 colaboradores, chamados aqui de "demais colaboradores", distribuídos pelas mais distintas funções como, por exemplo, analista de TI, analista da qualidade, auxiliar de produção, auxiliar comercial, assistente de compras, arquivista, vendedor, financeiro e recursos humanos. Os 19 colaboradores respondentes representam a totalidade de colaboradores da unidade de Ponta Grossa.

\section{O Caso estudado}

A organização objeto desta pesquisa, chamada aqui de Organização Alpha possui duas unidades de negócio específicas: Gráfica digital de impressão sob demanda e terceirização de peças industriais. A organização estudada possui uma grande experiência em fornecer produtos e serviços para organizações de renome mundial, sendo a indústria automotiva seu principal core business. A Organização Alpha localiza-se em três cidades do Estado do Paraná, nas cidades de Palmeira, Curitiba e Ponta Grossa. A Organização também é certificada nas normas ISO 9001: 2000 e ISO / TS 16949.

\section{Resultados}

Após a aplicação do instrumento de pesquisa, foram obtidos os resultados como conseqüência da percepção da alta administração e dos demais colaboradores da Organização Alpha. Nesta seção são apresentados os resultados de todas as Sete Dimensões do Conhecimento, sendo que esta pesquisa enfatiza a Quarta Dimensão do Conhecimento, "Estrutura Organizacional". As treze questões, relacionadas à dimensão "Estrutura Organizacional”, são parte integrante das cem ações de Gestão do Conhecimento da Terra (2007).

A aplicação deste instrumento de pesquisa teve o objetivo de verificar se a organização 
objeto de estudo possui um bom nível de execução de ações de Gestão do Conhecimento que a permitam criar uma ambiente propício à implementação da Inovação de Valor.

Para Terra $(2005,2007)$, as sete dimensões do conhecimento são:

1. Fatores Estratégicos e Papel da Alta Administração;

2. Sistemas de Informação;

3. Cultura e Valores Organizacionais;

4. Estrutura Organizacional;

5. Administração de Recursos Humanos;

6. Mensuração de Resultados;

7. Aprendizado com o Ambiente

De acordo com a aplicação do instrumento de pesquisa baseado no trabalho de Terra (2007), foi possível obter a percepção da alta administração e a percepção dos demais colaboradores a respeito das ações de Gestão do Conhecimento relacionadas à dimensão Estrutura Organizacional. A tabela 1 mostra a percepção da alta administração.

Tabela 1 - Resultados da alta administração

\begin{tabular}{ccccccc}
\hline DIMENSÃO & MÉDIA & $\begin{array}{c}\text { DESVIO } \\
\text { PADRÃO }\end{array}$ & $\begin{array}{c}\text { COEFICIENTE } \\
\text { DE VARIAÇÃO }\end{array}$ & MÍNIMO & MÁXIMO & AMPLITUDE \\
\hline $\mathbf{1}^{\mathbf{a}}$ DIMENSÃO & 3,650 & 0,49 & 13,51 & 3,10 & 4,20 & 1,10 \\
$\mathbf{2}^{\mathbf{a}}$ DIMENSÃo & 2,847 & 0,35 & 12,17 & 2,50 & 3,22 & 0,72 \\
$\mathbf{3}^{\mathbf{a}}$ DIMENSÃO & 4,066 & 0,60 & 14,74 & 3,53 & 4,68 & 1,16 \\
$\mathbf{4}^{\mathbf{a}}$ DIMENSÃO & 3,115 & 0,44 & 14,04 & 2,85 & 3,77 & 0,92 \\
$\mathbf{5}^{\mathbf{a}}$ DIMENSÃO & 3,310 & 0,45 & 13,47 & 2,68 & 3,72 & 1,04 \\
$\mathbf{6}^{\mathbf{a}}$ DIMENSÃO & 3,300 & 0,20 & 6,06 & 3,00 & 3,40 & 0,40 \\
$\mathbf{7}^{\mathbf{a}}$ DIMENSÃO & 3,250 & 0,53 & 16,38 & 2,60 & 3,90 & 1,30 \\
\hline \multicolumn{7}{c}{ Fonte: Os autores (2009) }
\end{tabular}

De acordo com a Tabela 1, a dimensão do conhecimento Estrutura Organizacional tem o segundo pior desempenho de acordo com o ponto de vista da alta administração, em comparação com as demais seis dimensões.

A alta administração exerce enorme influência nas quatro barreiras organizacionais (cognitiva, de recursos, motivação e política) para a implementação da Inovação de Valor. A baixa avaliação da alta administração dada para, a dimensão "Estrutura Organizacional, indica que a Organização Alpha possui potencial para melhorar este resultado, pois há divergência de percepção entre os gestores, principalmente representada pelos outros seis indicadores avaliados na tabela 1 .

A dimensão "Estrutura Organizacional" obteve o terceiro menor desvio-padrão, o quinto coeficiente de variação mais alto, a quarta nota mínima mais baixa e quarta nota máxima mais alta e a terceira menor amplitude. 
Devido à divergência de percepções demonstradas pela alta administração, existe a possibilidade de que tal divergência permita que a Organização Alpha reverta tal avaliação, uma vez que há gestores que a avaliam positivamente. Uma vez que haja uma unicidade de percepções, a possibilidade de criar-se um ambiente propício à Inovação de Valor torna-se bem maior. A alta administração exerce grande influência sobre as quatro barreiras organizacionais e a superação destas barreiras aumentam significativamente as chances de sucesso na implementação da Inovação de Valor.

Para facilitar a representação dos resultados obtidos da percepção da alta administração, estes resultados foram convertidos para escala de 0-100 de acordo com o gráfico a seguir:

Gráfico 1 - Resultados da Alta Administração em uma escala de 0-100

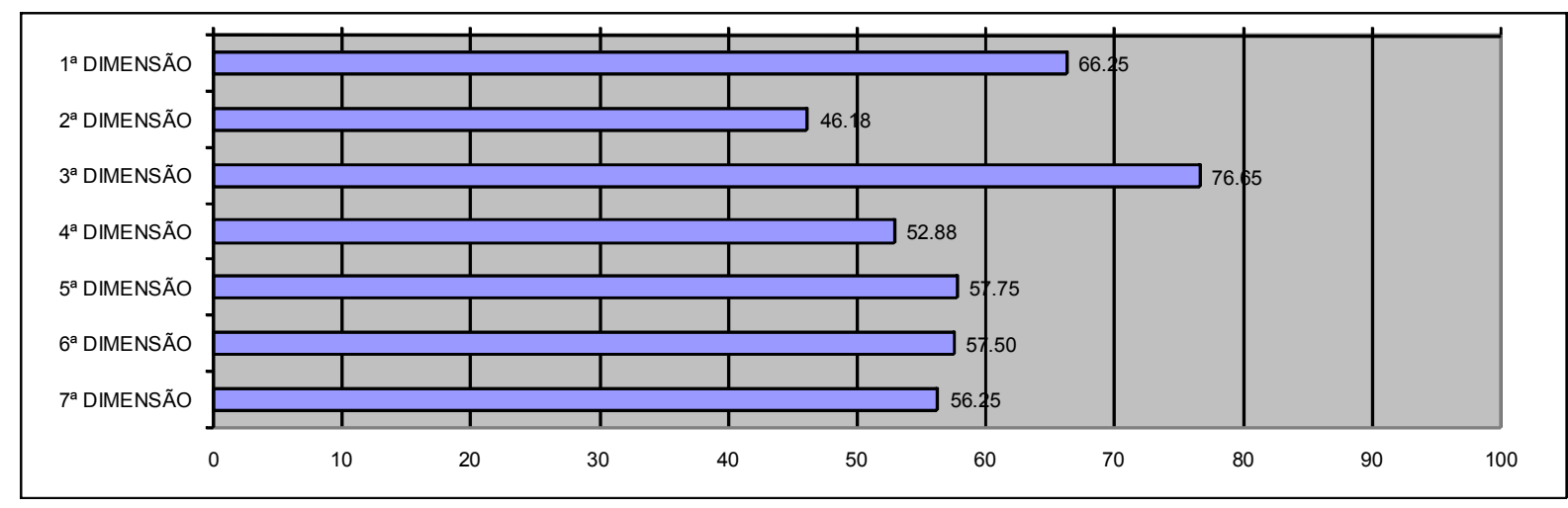

Fonte: Os autores (2009)

De acordo com o ponto de vista da alta administração, aquelas ações de Gestão do Conhecimento relacionadas à Estrutura Organizacional têm a segunda pior avaliação em comparação com as demais seis dimensões.

Na Tabela 2, é apresentada a média, desvio padrão, coeficiente de variação, mínimo, máximo e amplitude de acordo com o ponto de vista dos demais colaboradores da organização estudada.

Tabela 2 - Resultados dos demais colaboradores

\begin{tabular}{|c|c|c|c|c|c|c|}
\hline DIMENSÃO & MÉDIA & $\begin{array}{l}\text { DESVIO } \\
\text { PADRÃO }\end{array}$ & $\begin{array}{l}\text { COEFICIENTE } \\
\text { DE VARIAÇÃO }\end{array}$ & MÍNIMO & MÁXIMO & AMPLITUDE \\
\hline $1^{\mathrm{a}}$ DIMENSÃO & 3,447 & 0,71 & 20,52 & 2,40 & 4,60 & 2,20 \\
\hline $2^{\mathrm{a}}$ DIMENSÃO & 3,265 & 0,58 & 17,74 & 2,56 & 4,17 & 1,61 \\
\hline $3^{\mathrm{a}}$ DIMENSÃO & 3,705 & 0,60 & 16,20 & 2,42 & 4,63 & 2,21 \\
\hline $4^{\mathrm{a}}$ DIMENSÃO & 3,087 & 0,59 & 19,18 & 2,08 & 4,46 & 2,39 \\
\hline $5^{\mathrm{a}}$ DIMENSÃO & 3,123 & 0,61 & 19,61 & 2,40 & 4,52 & 2,12 \\
\hline $6^{\mathbf{a}}$ DIMENSÃO & 3,277 & 0,64 & 19,50 & 2,00 & 4,60 & 2,60 \\
\hline $7^{\mathrm{a}}$ DIMENSÃO & 2,833 & 0,77 & 27,13 & 2,00 & 4,40 & 2,40 \\
\hline
\end{tabular}

Fonte: Os autores (2009) 
Os demais colaboradores exercem enorme influência principalmente nas barreiras Cognitiva e Motivacional, das quatro barreiras organizacionais para execução da Inovação de Valor de Kim e Mauborgne (1997, 2005), Aiman-Smith et al. (2005) e Dillon, Lee e Matheson (2005).

Devido à divergência de percepções demonstradas pelos demais colaboradores, existe a possibilidade de que tal divergência permita também que a Organização Alpha reverta tal avaliação, uma vez que há colaboradores que a avaliam positivamente. Caso estes colaboradores que avaliaram esta dimensão positivamente sejam líderes no ponto de desequilíbrio, as chances de implementação da Inovação de Valor aumenta potencialmente. Vale ressaltar que a liderança no ponto de desequilíbrio exerce influência direta sobre as barreiras cognitivas e motivacionais e por esta razão que a Organização Alpha tem condições para reverter este quadro.

A dimensão Estrutura Organizacional obteve o segundo menor desvio-padrão, o quinto coeficiente de variação mais alto, a segunda nota mínima mais baixa e a terceira nota máxima mais alta e a quinta menor amplitude. Devido à divergência de percepções demonstradas pelos demais colaboradores, permite-se constatar que a Organização Alpha possui condições para reverter esta avaliação e criar um ambiente propício à Inovação de Valor.

No gráfico 2 a seguir, é possível verificar os resultados obtidos também em uma escala 0100, revelando agora a percepção dos demais colaboradores.

Gráfico 2 - Resultados dos demais colaboradores em uma escala de 0-100

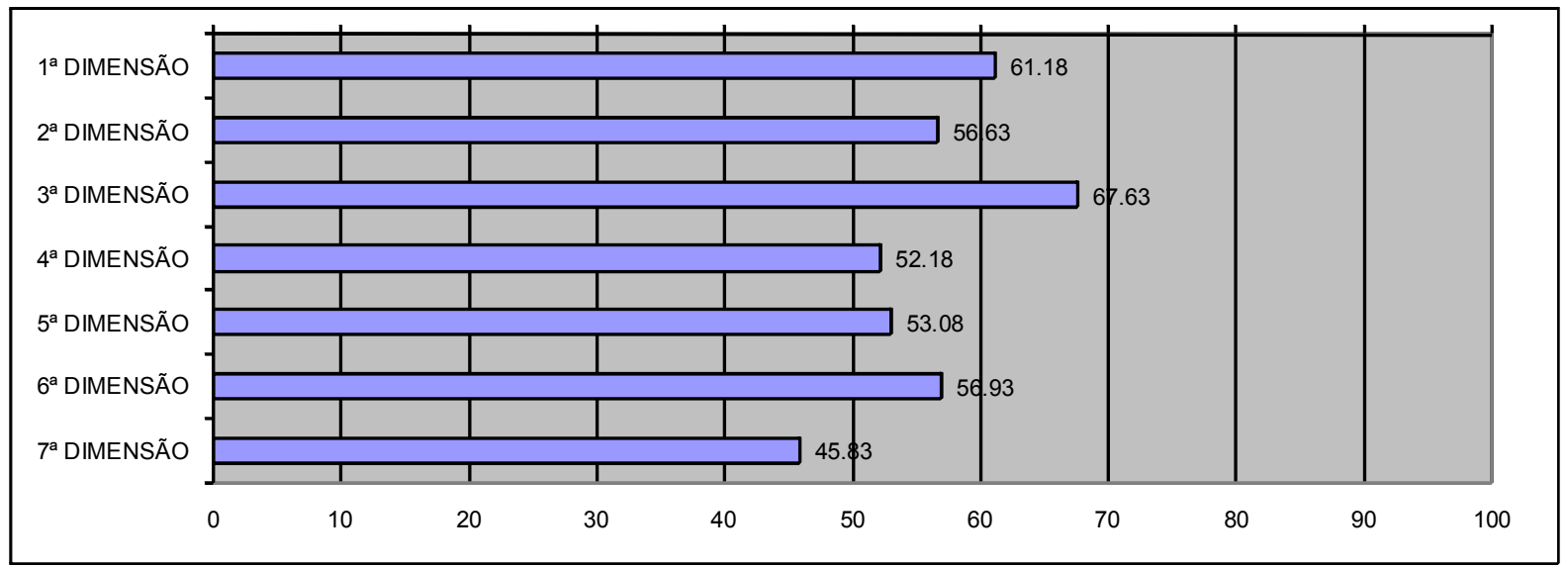

Fonte: Os autores (2009)

Nesta figura estão representadas as impressões dos demais colaboradores sobre o nível de utilização de ações de Gestão do Conhecimento relacionadas à Estrutura Organizacional. Igualmente como a alta administração, os demais colaboradores tem quase a mesma percepção, classificando a Estrutura Organizacional como a sexta melhor dimensão do conhecimento.

$\mathrm{Na}$ tabela 3, apresenta-se o resultado da percepção da alta administração referente às treze ações de Gestão de Conhecimento. 
Tabela 3 - Resultados da alta administração

\section{Q MÉdIA $\begin{gathered}\text { DESVIO } \\ \text { PADRÃO C. DE }\end{gathered}$ VARIAÇÃo MÍN MÁX AMPL INDICADORES DE AÇÕES DE GC}

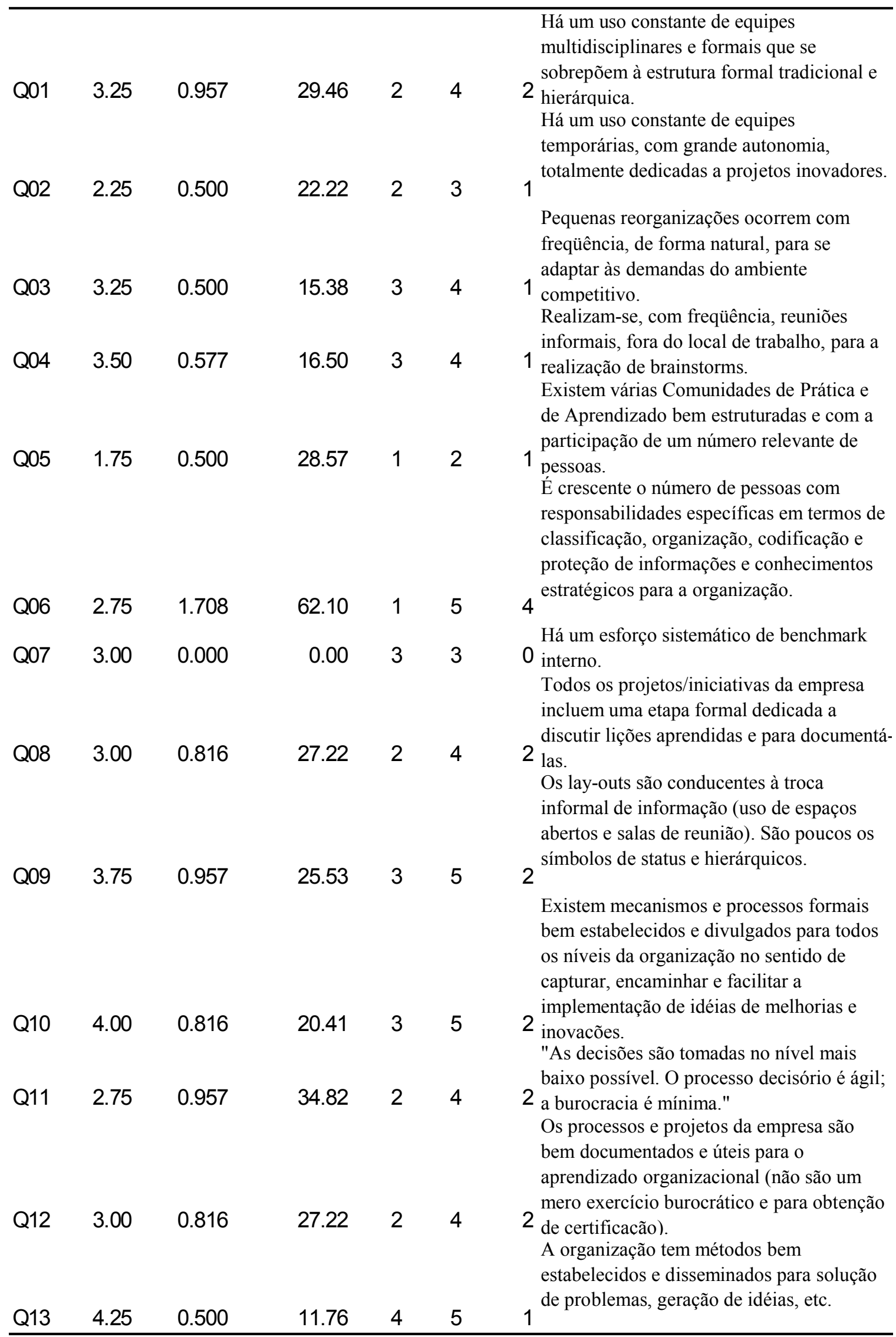

Fonte: Os autores (2009) 
As ações de Gestão do Conhecimento que tiveram melhor desempenho e sendo assim podem contribuir de maneira mais efetiva à implementação da Inovação de Valor foram:

$\mathrm{Na}$ questão número 01 que indaga se há um uso constante de equipes multidisciplinares e formais que se sobrepõem à estrutura formal tradicional e hierárquica. Tal questão tem a ver com a LPD que contribui para que a organização implemente a Inovação de Valor de forma satisfatória.

Na questão número 03 que indaga se pequenas reorganizações ocorrem com freqüência, de forma natural, para se adaptar às demandas do ambiente competitivo. Retrata a necessidade constante de propor reorganizações para melhorar a propagação do conhecimento e desta forma atender a demanda de mercado que dentro da teoria de Inovação de Valor, traduze-se em atender as necessidades do cliente mais importante da cadeia de valor a toda hora.

$\mathrm{Na}$ questão número 04 que indaga se são realizadas, com freqüência, reuniões informais, fora do local de trabalho, para a realização de brainstorms. A referida questão também tem a ver com a LPD, pois através desta ação permitem com que os líderes no ponto de desequilíbrio por meio de sua liderança possam influenciar os demais colaboradores por meio de ações informais.

$\mathrm{Na}$ questão número 09 que indaga se existem várias Comunidades de Prática e de Aprendizado bem estruturadas e com a participação de um número relevante de pessoas. Através da utilização das Comunidades de Prática torna-se possível romper a barreira cognitiva, pois por meio desta ação o conhecimento é criado, compartilhado e armazenado.

$\mathrm{Na}$ questão número 10 que indaga se existem mecanismos e processos formais bem estabelecidos e divulgados para todos os níveis da organização no sentido de capturar, encaminhar e facilitar a implementação de idéias de melhorias e inovações permite que LPD seja mais efetiva e que a implementação da Inovação de Valor seja facilitada.

$\mathrm{Na}$ questão número 13 que indaga se a organização tem métodos bem estabelecidos e disseminados para solução de problemas e geração de idéias são fundamentais para que boas idéias venham a se tornar inovação e como a Inovação de Valor permite a criação de novos espaços de mercado, a geração de idéias é de suma importância.

A tabela 4 apresenta a percepção dos demais colaboradores sobre as treze ações da dimensão "Estrutura Organizacional”. 


\section{Q MÉDIA $\begin{gathered}\text { DESVIO } \\ \text { PADRÃO C. DE }\end{gathered}$ VARIAÇÃo MÍN MÁX AMPL INDICADORES DE AÇÕES DE GC}

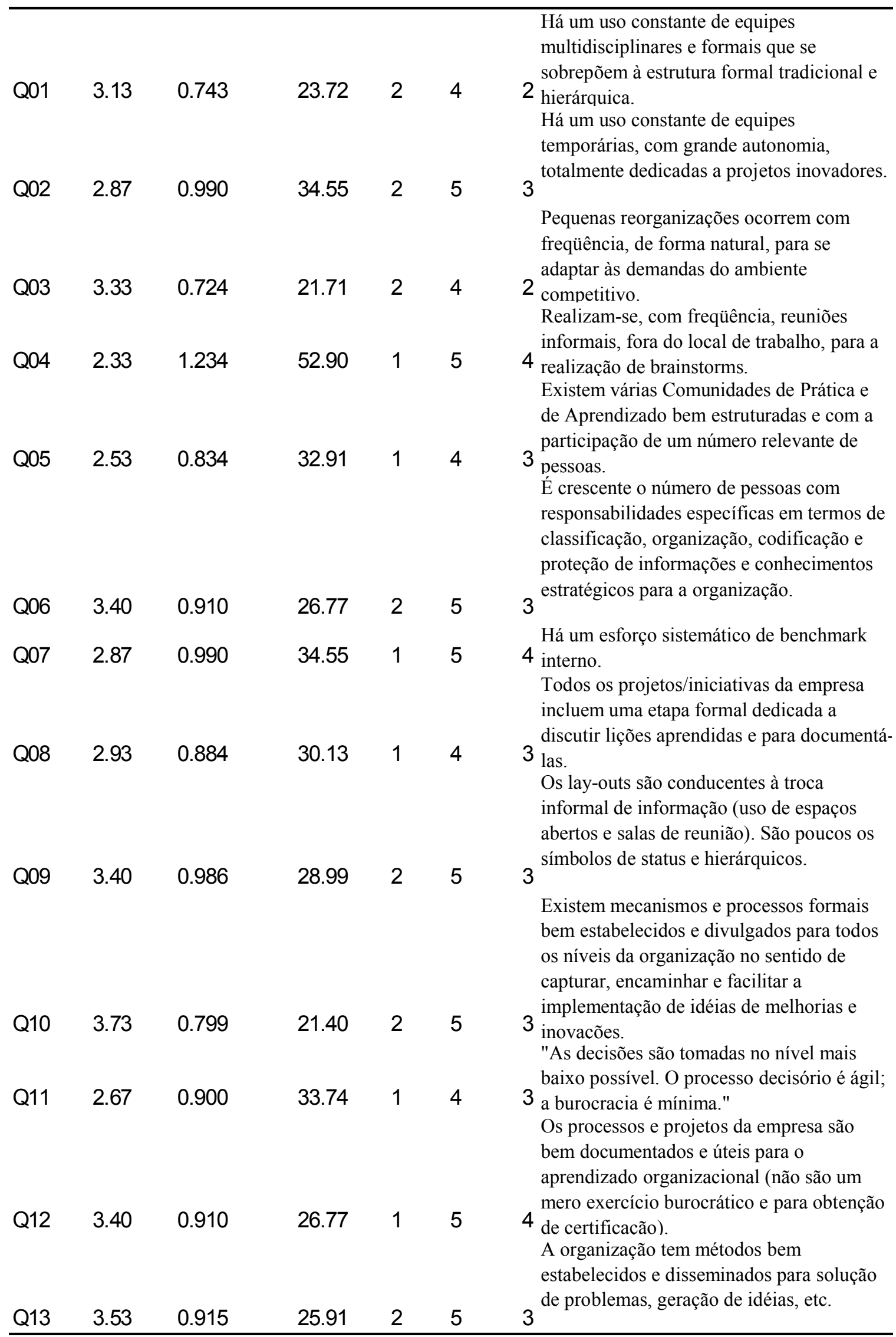

Fonte: Os autores (2009) 
Conforme tabela 4 a percepção dos demais colaboradores é similar à percepção da alta administração, divergindo apenas nas questões 04, 06 e 12 conforme a seguir:

A questão número 04 teve uma avaliação inferior à obtida pela alta administração permitindo constatar que esta ação não vem sendo propagada entre os colaboradores, como o brainstorm permite que a organização tenha idéias que podem se tornar inovações, a Organização Alpha deve prestar atenção a este quesito.

A questão número 06 que indaga se é crescente o número de pessoas com responsabilidades específicas em termos de classificação, organização, codificação e proteção de informações e conhecimentos estratégicos para a organização. A adesão desta ação permite que a organização rompa com o status quo vigente retratado pela barreira cognitiva e desta forma possibilite a geração de um ambiente propício à implementação da Inovação de Valor.

A questão número 12 que indaga se os processos e projetos da empresa são bem documentados e úteis para o aprendizado organizacional (não são um mero exercício burocrático e para obtenção de certificação). A gestão de documentos é importante para que a organização retenha o seu conhecimento organizacional, quanto ao aprendizado organizacional, este está intrinsecamente ligado ao conceito de Inovação de Valor que se refere à entrega de valor excepcionalmente superior ao cliente mais importante da cadeia de valor.

$\mathrm{Na}$ próxima seção serão representadas as conclusões obtidas dos resultados desta análise sobre a luz da teoria e conceitos sobre Inovação de Valor.

\section{Conclusões}

De acordo com as evidências coletadas no presente documento, as treze ações relacionadas à quarta dimensão do Conhecimento, Estrutura Organizacional, receberam a segunda pior avaliação, tanto pela alta administração, quanto pelos demais colaboradores. O resultado foi 52,88 para a alta administração e 52,18 para os demais colaboradores.

Baseado nestes resultados, a Organização Alpha deve prestar mais atenção na baixa avaliação em relação às demais seis dimensões. Entretanto, tanto a alta administração, quanto os demais colaboradores possuem divergência de opiniões significativas por boa parte dos membros que compõem cada um dos dois grupos.

Se organização objeto de estudo conseguir reduzir a divergência de percepções e implementar um plano de ação para alterar o nível de avaliação da dimensão "Estrutura Organizacional”, poderá então criar um ambiente propício para implementação da Inovação de Valor, principalmente rompendo as barreiras organizacionais (cognitiva, de recursos, motivação e política), todas estas relacionadas à aplicação da teoria de Inovação de Valor e sustentadas pela 
liderança no ponto de desequilíbrio.

Superando estas quatro barreiras, será possível para Organização Alpha criar um ambiente propício para implementar a Inovação de Valor.

Alinhando as percepções dos membros que compõem a Organização Alpha, pode-se então romper as barreiras organizacionais enfrentadas, quando uma organização decide implementar uma nova estratégia, especialmente no caso da Inovação de Valor, que impacta diretamente sobre a forma como a organização faz negócios, uma vez que a Inovação de Valor requer uma nova forma de fazer negócios, rompendo com o status quo vigente.

Com base nos resultados da análise das treze ações de Gestão do Conhecimento relacionadas à Estrutura Organizacional, pode-se concluir que a organização estudada possui ações de Gestão do Conhecimento que necessitariam ser ampliadas, pois são aquelas que tiveram baixa avaliação por parte da alta administração e por parte dos demais colaboradores como às ações vinculadas à Equipes temporárias e autônomas, Comunidades de prática, Benchmark interno, Lições aprendidas e Processo decisório. Implementando medidas para que a avaliação destas possibilite que haja mais ações em nível suficiente para criar um ambiente propício para implementar a Inovação de Valor sob o prima da Estrutura Organizacional.

No entanto, deve-se compreender que se faz necessário também mencionar que as outras dimensões do conhecimento também têm um impacto importante no sucesso da implementação da estratégia de Inovação de Valor e, sobre este aspecto, demonstrou-se que a organização estudada possui potencial para a implementação devido à boa avaliação obtida nas demais dimensões.

Vale ressaltar que a organização estudada, deve prestar atenção além da dimensão "Estrutura Organizacional" que teve o segundo pior desempenho para a alta administração e demais colaboradores, mas também com a dimensão "Sistemas de Informação" segundo a percepção da alta administração, e a dimensão "Aprendizagem com o Ambiente" segundo a percepção dos demais colaboradores, pois nestas duas dimensões citadas, a organização enfrenta sua pior avaliação de acordo com o ponto de vista da alta administração e demais colaboradores respectivamente.

Tanto a dimensão relacionada aos Sistemas de Informação, quanto à Aprendizagem com o Ambiente, devem prever a adoção de políticas para que haja um melhor desempenho das mesmas, em virtude de ambas estarem fortemente relacionadas ao compartilhamento do conhecimento. Uma vez que a Inovação de Valor é centrada no cliente mais valioso da cadeia de valor, a aprendizagem com ambiente externo pode trazer informações importantes que irão afetar na execução de um novo modelo de negócio e conseqüentemente em seu eventual sucesso. 


\begin{abstract}
The present paper demonstrated the use of thirteen actions of Knowledge Management related with the dimension "Organizational Structure" of Terra $(2005,2007)$ to allow the implementation of Value Innovation by Kim and Mauborgne (1997, 2005), Dillon, Lee and Matheson (2005) and Aiman-Smith et al. (2005) in a Brazilian organization whose has two distinct business models, digital graphic print on demand and supply of industrial parts. The bibliography was around the authors Kim and Mauborgne and several authors of Knowledge Management. This research was applied, quantitative, exploratory and inductive. The instrument used for data collection was a questionnaire based on one hundred actions of Knowledge Management of Terra (2007). The results demonstrate that the Organization Alpha has eight actions of Knowledge Management used in high level which makes possible the implementation of Value Innovation. However, it is necessary to implement organizational policies aimed at raising the level of use of the actions of knowledge management related to the dimension "Organizational Structure". There is an opportunity for improvement to reduce the differences of perceptions between high administration and the rest of collaborators, once two actions were quite different insights, since, by reducing the differences of perceptions, it allows to create a propitious environment to the implementation of Value of Innovation. The organization object of study must implement policies based on the concepts and principles of Value Innovation to the actions of knowledge management can be better exploited and, thus, generate wealth and high growth.
\end{abstract}

Key-words: knowledge management actions, organizational structure, value innovation.

\title{
Referências
}

AIMAN-SMITH, L.; GOODRICH, N.; ROBERTS, D.; SCINTA, J. Assessing your organization's potential for value innovation. Research Technology Management. v. 48, n. 2, p. 37-42, 2005.

CHESBROUGH, H.. Open innovation: the new imperative for creating and profiting from technology. Boston: Harvard Business School Publishing, 2006.

CORTES, E.; SAEZ, P.; ORTEGA, E. Organizational structure features supporting knowledge management processes. Journal of Knowledge Management. v. 11, n. 4, p. 45-57, 2007.

cross ${ }^{\text {eff }}$

DAVENPORT, T.; PRUSAK, L. Conhecimento empresarial: como as organizações gerenciam o seu capital intelectual. Rio de Janeiro: Elsevier, 2003.

DILLON, T.; LEE, R.; MATHESON, D. Value innovation: passport to wealth creation. Research Technology Management. v. 48, n. 2, p. 22-36, 2005.

DRUCKER, P. The essential Drucker: selections from the management works of Peter F. Drucker. Oxford: Butterworth-Heinemann, 2007.

HÜBLER, E.; PEREIRA, M. O design como inovação na perspectiva emergente das experiências de consumo. In: ENCONTRO NACIONAL DE ENGENHARIA DE PRODUÇÃO, 25., 2005, Porto Alegre. Anais... Porto Alegre: ABEPRO, 2005.

KIM, W.; MAUBORGNE, R. Value Innovation: The Strategic Logic of High Growth. Harvard Business Review. v. 75, n. 1, p. 103-112, 1997.

KIM, W.; MAUBORGNE, R. Tipping Point Leadership. Harvard Business Review. v. 81, n. 4, p. 60-69, 2003.

KIM, W.; MAUBORGNE, R. Blue Ocean Strategy: how to create uncontested market space and make the competition irrelevant. Boston: Harvard Business School Publishing, 2005. 
KUEMMERLE, W. Home base and knowledge management in international ventures. Journal of Business Venturing. v. 17, n. 2, p. 99-122, 2002.

cross ref

LAKATOS, E.; MARCONI, M. Fundamentos de metodologia científica. São Paulo: Atlas, 2007.

NONAKA, I.; TAKEUCHI, H. The knowledge-creating company: how Japanese companies create the dynamics of innovation. New York: Oxford, 1995.

NONAKA, I; VON KROGH, G.; VOELPEL, S. Organizational Knowledge Creation Theory: Evolutionary Paths and Future Advances. Organization Studies. v. 27, n. 8, p. 1179-1208, 2006.

cross ${ }^{\text {ref }}$

REIS, D. R.. Gestão da Inovação Tecnológica. Barueri: Manole, 2008.

TERRA, J. Gestão do Conhecimento: o grande desafio empresarial. São Paulo: Campus, 2005.

TERRA, J. Gestão do Conhecimento: 7 Dimensões e 100 Práticas Gerenciais do Terraforum. 2007. Disponível $\quad$ em: $\quad<$ http://www.terraforum.com.br/sites/terraforum/Biblioteca/GC__7_Dimens\%C3\%B5es_e_100_pr\%C3\%A1ticas_gerenciais.pdf $>$. Acesso em: 21 nov. 2007.

TIDD, J.; BESSANT, J.; PAVITT, K. Managing innovation: integrating technological, market and organizational change. Chinchester: Wiley, 2005.

\section{Dados dos autores:}

Nome completo: Ricardo Monteiro de Carvalho

Filiação institucional: UTFPR

Departamento: PPGEP

Função ou cargo ocupado: Mestrando do PPGEP

Endereço completo para correspondência (bairro, cidade, estado, país e CEP):

PPGEP - UTFPR // Av. Monteiro Lobato, Km 04, s/n - Sta. Monica // CEP: 84016-210 // Ponta

Grossa // Paraná.

Telefones para contato: (42) 9102-6900; (042) 3220-4805

e-mail:rmdecarvalho@yahoo.com.br

Nome completo: Dálcio Roberto dos Reis

Filiação institucional: UTFPR

Departamento: PPGEP

Função ou cargo ocupado: Doutor, professor do PPGEP

Endereço completo para correspondência (bairro, cidade, estado, país e CEP):

PPGEP - UTFPR // Av. Monteiro Lobato, Km 04, s/n - Sta. Monica // CEP: 84016-210 // Ponta Grossa // Paraná. 
Telefones para contato: (042) 3220-4805

e-mail:dalcio@utfpr.edu.br

Nome completo: Bruno Pedroso

Filiação institucional: UTFPR

Departamento: PPGEP

Função ou cargo ocupado: Mestrando do PPGEP

Endereço completo para correspondência (bairro, cidade, estado, país e CEP):

PPGEP - UTFPR // Av. Monteiro Lobato, Km 04, s/n - Sta. Monica // CEP: 84016-210 // Ponta Grossa // Paraná.

Telefones para contato: (042) 3220-4805

e-mail: brunops3@brturbo.com.br

Recebido para publicação em: 14/08/2009

Aceito para publicação em: 10/11/2009 